\title{
Role of modelling in plant disease management
}

\author{
Praneet Chauhan* and Sunita Chandel
}

${ }^{1}$ Department of Plant Pathology, Dr. Y.S. Parmar University of Horticulture and Forestry, Nauni, Solan (H.P.) India

\section{ARITCLE INFO}

Received : 27.11 .2017

Accepted : 30.03 .2018

\section{KEY WORDS :}

Epidemic, Forecasting, Modelling, Simulation

*Corresponding author:

chauhanpraneet78@gmail.com

\begin{abstract}
Indian's economy is agricultural based. Agriculture provides maximum employment in the country. Unfortunately, crop production is heavily affected by the pests and diseases. In addition to refinement in the existing management practices, there is a need for simulation models to assess the potential of emerging pathogens for a given crop production system and also shift in pathogen populations/fitness that may demand modifications in current production systems. Forecasting models which allows investigating multiple scenarios and interactions simultaneously has become most important for disease prediction, impact assessment and application of disease management measures. Many weather driven epidemiological models have been developed and used to predict plant disease epidemics under variable climate. Most forecasting models are meant for tactical and strategic decisions. Similarly, the Mill's Table also had been modified for Apple scab epidemic under H.P conditions. Moreover, remote sensing and image analysis have been used in plant diseases epidemiology to forecast the plant diseases. These epidemiological tools have been designed to help the farmers in enhancing the efficiency and adequacy of disease management. A complete knowledge of these epidemiological tools provide quick, fast and accurate prediction of disease and helps in timely disease control.
\end{abstract}

How to view point the article : Chauhan, Praneet and Chandel, Sunita (2018). Role of modelling in plant disease management. Internat. J. Plant Protec., 11(1) : 124-134, DOI : 10.15740/HAS/ IJPP/11.1/124-134. 